УДК 621.315 .592

\title{
Влияние никеля и меди, введенных при комнатной температуре, на рекомбинационные свойства протяженных дефектов в кремнии
}

\author{
() В.И. Орлов ${ }^{1,2}$, Н.А. Ярыкин ${ }^{1}$, Е.Б. Якимов ${ }^{1,3}$ \\ ${ }^{1}$ Институт проблем технологии микроэлектроники и особочистых материалов Российской академии наук, \\ 142432 Черноголовка, Россия \\ ${ }^{2}$ Институт фризики твердого тела Российской академии наук, \\ 142432 Черноголовка, Россия \\ ${ }^{3}$ Национальный исследовательский технологический университет „МИСиС“, \\ 119049 Москва, Россия \\ E-mail: orlov@issp.ac.ru
}

(Поступила в Редакцию 13 ноября 2018 г.

В окончательной редакции 20 ноября 2018 r.

Принята к публикации 20 ноября 2018 г.)

\begin{abstract}
Методами тока, индуцированного электронным или оптическим пучками, исследовано изменение рекомбинационных свойств индивидуальных дислокаций и дислокационных следов в кремнии в результате диффузии никеля и меди в процессе химико-механической полировки при комнатной температуре. Обнаружено, что введение никеля приводит к росту рекомбинационной активности как дислокаций, так и дислокационных следов. Введение меди не вызывает существенного изменения контраста протяженных дефектов.
\end{abstract}

DOI: 10.21883/FTP.2019.04.47672.9020

\section{1. Введение}

Известно, что дислокации могут существенно влиять на электрофизические свойства кремния $[1,2]$. В последние годы эта тематика получила новое развитие, так как пластины мультикристаллического кремния для солнечных элементов содержат высокую плотность дислокаций. Дислокации генерируются вследствие термических напряжений, возникающих в процессе охлаждения слитков и при различных технологических операциях формирования фотоэлектрических структур. Дислокации в кремнии, движущиеся при промежуточных температуpax, формируют квазидвумерные протяженные дефекты в плоскости скольжения [3,4]. Эти дефекты, известные как дислокационные следы (ДС), так же как и сами дислокации, обладают электрической активностью и выявляются методами тока, индуцированного электронным (EBIC) или световым (LBIC) пучками [4-9].

Природа электрической активности ДС, так же как дислокаций, несмотря на многолетние исследования, остается темой для дискуссий. Она может определяться как специфической конфигурацией атомов кремния (собственная активность), так и декорированием структурных дефектов примесями. Однозначных доказательств собственной природы электрической активности не получено ни для дислокаций, ни для ДС. В то же время возрастание рекомбинационной активности дислокаций вследствие загрязнения металлами показано для целого ряда примесей [2,10-14]. Что же касается дислокационных следов, то влияние металлов на их рекомбинационные свойства изучалось лишь в нескольких работах [4,5,14-16], в которых примесь вводилась путем диффузии при температурах, сравнимых с темпе- ратурой деформации, что могло существенным образом модифицировать собственную структуру дефектов. При понижении температуры диффузии влияние металлов на электрическую активность дефектов в пластически деформированном кремнии уменьшалось [17], что может быть связано с существованием энергетического барьера, который замедляет реакции металлов со структурными дефектами при пониженных температурах. Другая очевидная причина заключается в том, что концентрация примеси может быть недостаточной, например, из-за уменьшения ее предельной растворимости.

Последняя причина не актуальна для примесей меди и никеля, так как показано, что химико-механическая полировка кремния в суспензии, загрязненной этими примесями, вводит их в концентрациях, которые на порядки превышают пределы их растворимости при комнатной температуре $[18,19]$. Кроме того, коэффициенты диффузии этих примесей столь велики, что они могут проникать на десятки и сотни микрометров при комнатной температуре. В настоящей работе эта уникальная возможность использована для исследования взаимодействия дефектов, созданных пластической деформацией, т.е. дислокаций и ДС, с примесями меди и никеля при комнатной температуре.

\section{2. Методика эксперимента}

В работе использовался бездислокационный монокристаллический кремний, выращенный методом Чохральского. Образцы для деформации вырезались из коммерчески доступных пластин $p$ - и $n$-типа проводимости в форме прямоугольных призм размером $30 \times 4 \times 0.7 \mathrm{Mм}$ 
с ориентациями граней $\{100\},\{110\},\{110\}$ в последовательности убывания площадей. Перед введением дислокаций образцы химически полировались для удаления неконтролируемых источников дислокаций. Индивидуальные дислокационные полупетли вводились от концентраторов напряжений на поверхности $\{100\}$, которые создавались уколами алмазного индентора. Деформация осуществлялась методом четырехопорного изгиба вокруг оси $\langle 110\rangle$ при температуре $600^{\circ} \mathrm{C}$. При такой схеме нагружения одна часть образца подвергается сжимающим, а другая - растягивающим напряжениям.

Химико-механическая полировка осуществлялась с использованием нетканого химически стойкого полировального сукна, увлажненного коммерчески доступ-

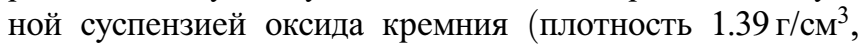
размер частиц $\sim 40 \mathrm{Hм})$, разбавленной в 10 раз $20 \%$-м раствором КОН. Обычно скорость удаления материала составляла $0.1-0.5$ мкм/мин. Загрязнение суспензии металлами осуществлялось путем добавления небольшого количества азотной кислоты, в которой были растворены никель или медь. Эта операция практически не изменяла щелочной характер эмульсии ( $\mathrm{pH} \sim 10)$. Итоговая концентрация металлов была 100 мкг/мл.

Рекомбинационные свойства протяженных дефектов исследовались методами тока, индуцированного электронным (EBIC) или оптическим (LBIC) пучками. Для EBIC- и LBIC-исследований на образцах формировались полупрозрачные барьеры Шоттки путем напыления тонких слоев $\mathrm{Au}$ для образцов $n$-типа и $\mathrm{Al}$ для образцов $p$-типа проводимости. Омические контакты создавались путем втирания пасты $\mathrm{AlGa}$ в тыльную сторону образцов. Энергия пучка электронов (ЕВIC) составляла 35 кэВ (глубина проникновения $\sim 9$ мкм). B методике LBIC использовался лазер с длиной волны 980 нм (глубина проникновения 110 мкм). Величина контраста вычислялась по формуле $C=1-I_{C} / I_{C 0}$, где $I_{C}$ и $I_{C 0}$ - величина тока, собираемого барьером Шоттки вблизи дефекта и вдали от него соответственно.

\section{3. Результаты и обсуждение}

Ранее было показано [20], что дислокационные следы формируются только в области, обметенной одним из трех сегментов гексагональной дислокационной полупетли, а именно за 60-градусной дислокацией, у которой лидирующей является 90-градусная частичная дислокация. При использованной в настоящей работе кристаллографической ориентации дислокационные следы на сжатой стороне формируются за одним из боковых сегментов каждой дислокационной полупетли. За каким именно, определяется вектором Бюргерса конкретной дислокации, который может иметь одно из двух равновероятных направлений в обеих возможных плоскостях скольжения $\{111\}$. На растянутой стороне ДС формируются за донным сегментом полупетли [20] и в настоящей работе не рассматриваются.
На рисунке приведены EBIC- и LBIC-изображения одного и того же фрагмента сжатой стороны образца кремния $n$-типа, где дефекты были введены от трех уколов алмазным индентором. Место одного из уколов отмечено кружком. Уколы были химически сполированы перед финальным разгоном полупетель. Места выхода боковых сегментов дислокационной полупетли на поверхность наблюдения указаны белыми стрелками. Изображения ДС в режиме EBIC выглядят как длинные темные линии, расположенные вдоль направления $\langle 110\rangle$ (черные стрелки). Как было сказано выше, ДС формируются только за одним из боковых сегментов, что хорошо видно для правой и левой полупетель. В то же время ДС формируются с обеих сторон от укола в центре фрагмента. Это свидетельствуе о зарождении дислокационных полупетель с различными векторами Бюргерса. Обычно от каждого укола зарождалось от 1 до 5 дислокационных полупетель. Разбросом этого числа, скорее всего, определяется вариация величины контраста дефектов, сформировавшихся от разных уколов.

Как и ожидалось, изображения в режимах ЕВIC и LBIC качественно схожи (рисунок, $a$ и $c$ ), хотя пространственное разрешение LBIC ниже из-за большего диаметра пучка. Основное различие связано с тем, что излучение с длиной волны 980 нм проникает намного глубже, чем электронный пучок. Поскольку плоскости скольжения дислокаций в данной геометрии отклонены от нормали к поверхности наблюдения на угол $\sim 35^{\circ}$, большая глубина проникновения светового пучка позволяет получать квазитрехмерное изображение ДС. Видно, в частности, что оба ДС в центральной части изображения на рисунке, $c$ наклонены в одну и ту же сторону: плавно убывающий контраст с левой стороны соответствует заглубленной части ДС. Ширина контраста $\sim 120$ мкм соответствует глубине $\sim 180$ мкм.

Контрольная химико-механическая полировка образца с введенными дефектами в номинально чистой суспензии показала, что заметного изменения рекомбинационных контрастов EBIC и LBIC не происходит. В то же время загрязнение суспензии никелем приводит к существенному возрастанию контраста как дислокаций, так и дислокационных следов (рисунок, $b$ и $d)$. В кремнии $n$-типа ЕВIC-контраст дислокаций увеличивается в 1.5-2 раза и в 2-5 раз для ДС. Для кремния $p$-типа проводимости эффект более яркий, так как EBIC-контраст дислокаций после деформации очень слабый и часто ниже предела чувствительности EBIC-измерений $(\sim 1 \%)$. После загрязнения никелем контраст дислокаций возрастает до $\sim 10 \%$, а контраст ДС увеличивается в $~ 2$ раза.

Таким образом, в процессе химико-механической полировки при комнатной температуре в загрязненной $\mathrm{Ni}$ суспензии образуются рекомбинационно-активные центры, локализованные на дислокациях и ДС. Следует отметить, что условия формирования рекомбинационных центров при низкотемпературном введении никеля коренным образом отличаются от тех, которые 

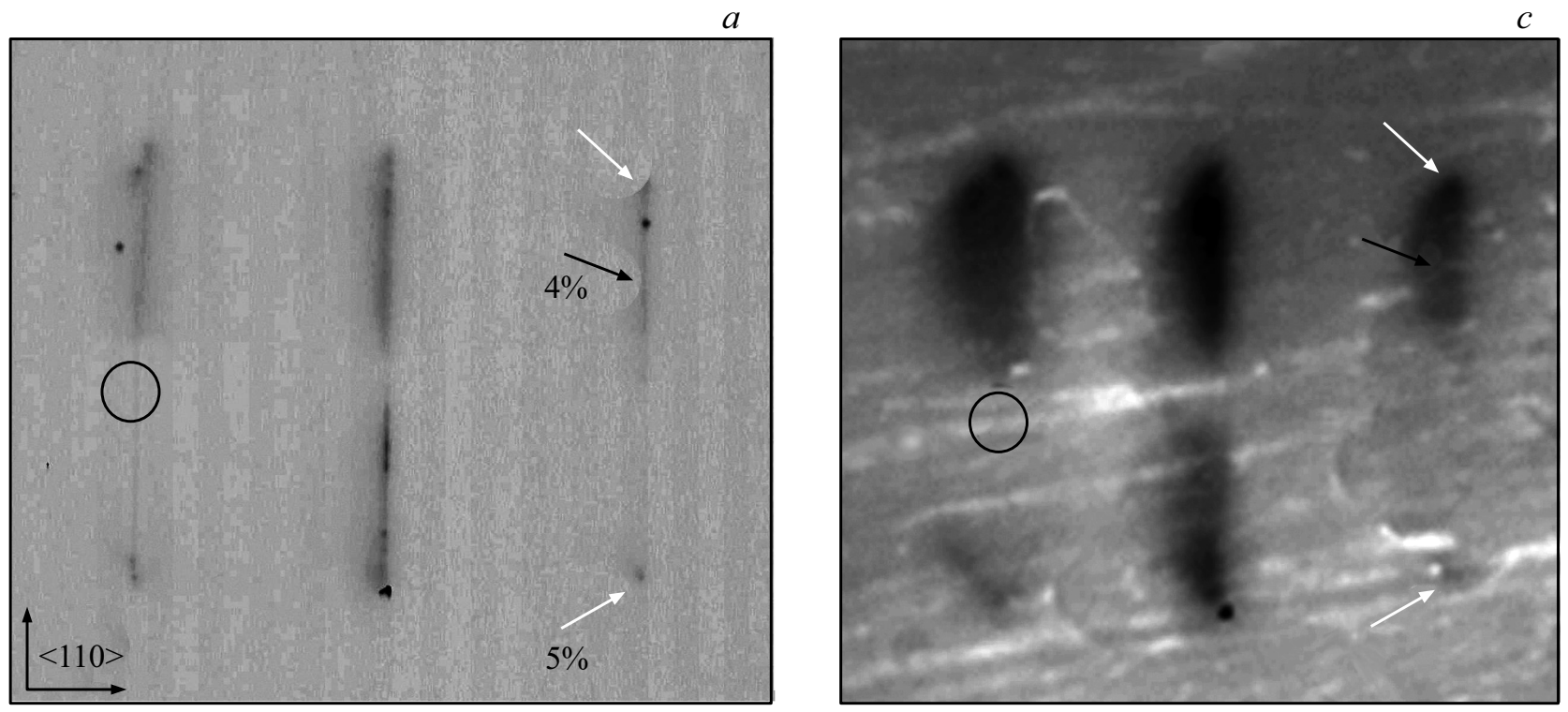

$b$

$d$
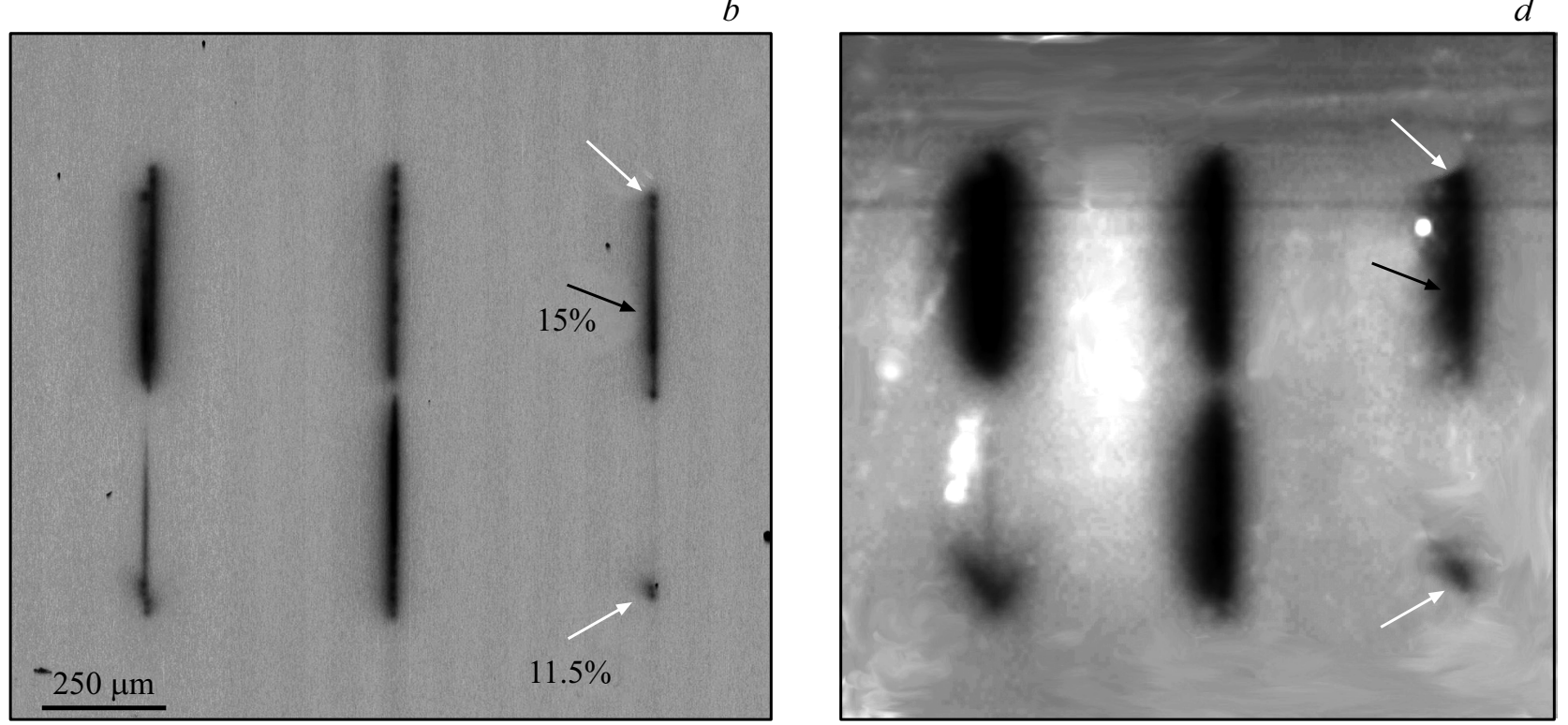

EBIC- $(a, b)$ и LBIC- $(c, d)$ изображения одного и того же места на поверхности $\{100\}$ на стороне сжатия деформированного образца $n$-Si до $(a, c)$ и после $(b, d)$ введения никеля. Белые стрелки указывают на контраст, связанный с дислокациями, черные на дислокационные следы. Указаны величины контраста в \%. Кружок - место зарождения дислокационной полупетли.

реализуются при диффузии при высоких температурах $\left(500-700^{\circ} \mathrm{C}\right)$. Электрическая активность дефектов после высокотемпературных воздействий часто связывается с формированием преципитатов силицидов [13], тогда как рост второй фазы при околокомнатных температурах маловероятен. Более вероятно взаимодействие отдельных атомов металлов с несовершенствами кристалла, хотя возможно также и образование агломератов быстро диффундирующих примесей. Тем не менее представляет интерес качественное сравнение с результатами работ по высокотемпературному введению металлов.

Увеличение рекомбинационного контраста дислокаций вследствие введения никеля при комнатной температуре согласуется с ранее опубликованными результата- ми по высокотемпературной диффузии, хотя конкретные механизмы изменения электрофизических свойств дислокаций и в том, и другом случае остаются непонятыми. Однако увеличение контраста ДС, обнаруженное в настоящей работе, не согласуется с данными по диффузии никеля при высокой температуре. В работе [21] было показано, что введение никеля при $600^{\circ} \mathrm{C}$ увеличивает только LBIC-контраст дислокаций, но не ДС. Можно назвать две вероятные причины этого противоречия. Во-первых, введение никеля в [21] осуществлялось в образцы, которые после пластической деформации были отожжены при $820^{\circ} \mathrm{C}$, что существенно выше температуры деформации в нашей работе. Известно [22], что электрические свойства ДС изменяются при значительно 
более низкой температуре. Поэтому термообработка при $820^{\circ} \mathrm{C}$ могла разрушить те дефекты, на которых зарождаются связанные с никелем центры, обнаруженные в данной работе. Во-вторых, если даже принять, что эти прекурсоры рекомбинационно-активных центров достаточно стабильны, энергия связи атомов никеля на этих дефектах может быть низкой и рекомбинационноактивные центры не образуются при $600^{\circ} \mathrm{C}$.

Как уже отмечалось выше, контраст от ДС на стороне сжатия в данной кристаллографической ориентации формируется только за одним из боковых сегментов дислокационной полупетли. Важно отметить, что существенное увеличение этого контраста вследствие введения никеля не сопровождается появлением какоголибо контраста за противоположным сегментом полупетли (правая и левая полупетли на рисунке). Это наблюдение является косвенным указанием на то, что не существует „невидимых“ (т. е. электрически неактивных) ДС за сегментом с лидирующей 30-градусной частичной дислокацией.

В отличие от никеля, использование меди в качестве примеси при химико-механической полировке не приводило к существенным изменениям в величине рекомбинационного контраста как дислокаций, так и дислокационных следов. Это весьма неожиданный результат, поскольку было показано, что медь формирует при комнатной температуре комплексы с точечными дефектами как вакансионного, так и межузельного типов [23-25]. Более того, диффузия меди при высоких температурах приводила к повышению контраста ДС, хотя контраст самих дислокаций при этом практически не изменялся $[15,16]$.

Работа выполнена в рамках Государственного задания ИПТМ РАН (№ 075-00475-19) и ИФТТ РАН.

\section{Список литературы}

[1] W. Schroter, H. Cerva. Sol. St. Phenomena, 85-86, 67 (2002).

[2] M. Seibt, V.V. Kveder. In: Advanced Silicon Materials for Photovoltaic Applications, ed. by S. Pizzini (John Wiley \& Sons, 2012) p. 127.

[3] I.E. Bondarenko, V.G. Eremenko, B.Ya. Farber, V.I. Nikitenko, E.B. Yakimov. Phys. Status Solidi A, 68 (1), 53 (1981).

[4] I.E. Bondarenko, H. Blumtritt, J. Heydenreich, V.V. Kazmiruk, E.B. Yakimov. Phys. Status Solidi A, 95 (1), 173 (1986).

[5] H. Alexander, S. Dietrich, M. Hühne, M. Kolbe, G. Weber. Phys. Status Solidi A, 117 (2), 417 (1990).

[6] I.E. Bondarenko, E.B. Yakimov. Phys. Status Solidi A, 122 (1), 121 (1990)

[7] В.И. Орлов, О.В. Феклисова, Е.Б. Якимов. ФТП, 49, 737 (2015).

[8] A. Cavallini, A. Castaldini. J. de Phys., IV Colloque, 01 (C6), C6-89 (1991).

[9] V.I. Orlov, E.B. Yakimov, Superlatt. Microstruct., 99, 202 (2016).

[10] T.S. Fell, P.R. Wilshaw, M.D. De Coteau. Phys. Stat. Solidi A, 138 (2), 695 (1993).
[11] S. Kusanagi, T. Sekiguchi, B. Shen, K. Sumino. Mater. Sci. Techn., 11 (7), 685 (1995).

[12] M. Kittler, C. Ulhaq-Bouillet, V. Higgs. Mater. Sci. Engin. B, 24 (1), 48 (1994).

[13] M. Seibt, V. Kveder, W. Schroter, O. Voß. Phys. Status Solidi A, $202(5), 911$ (2005).

[14] О.В. Феклисова, Е.Б. Якимов. ФТТ, 53, 1175 (2011).

[15] O.V. Feklisova, X. Yu, D. Yang, E.B. Yakimov. Phys. Status Solidi C, 9, 1942 (2012).

[16] О.В. Феклисова, Е.Б. Якимов. ФТП, 49 (6), 732 (2015).

[17] M. Seibt, V. Kveder, W. Schroter, O. Voß. Phys. Status Solidi A, $202(5), 911$ (2005).

[18] T. Zundel, J. Weber, B. Benson, P.O. Hahn, A. Schnegg, H. Prigge. Appl. Phys. Lett., 53 (15), 1426 (1988).

[19] N. Yarykin, J. Weber. Appl. Phys. Lett., 109, 102101 (2016).

[20] V.I. Orlov, E.B. Yakimov, N. Yarykin. Phys. Status Solidi C, 14, 1700074 (2017).

[21] V. Kveder, M. Khorosheva, M. Seibt. Materials Today: Proceedings, 5, 14757 (2018).

[22] В.Г. Еременко, Е.Б. Якимов. Письма ЖЭТФ, 26 (2), 72 (1977).

[23] Н. А. Ярыкин, J. Weber. ФТП, 49 (6), 728 (2015).

[24] Н. А. Ярыкин, J. Weber. ФТП, 44 (8), 1017 (2010).

[25] N. Yarykin, J. Weber. Phys. Rev. B, 83, 125207 (2011).

Редактор Л.В. Шаронова

\section{Impact of nickel and copper in-diffusion at room temperature on recombination properties of extended defects in silicon}

\author{
V. Orlov ${ }^{1,2}$, N. Yarykin ${ }^{1}$, E. Yakimov ${ }^{1,3}$ \\ ${ }^{1}$ Institute of Microelectronics Technology, \\ Russian Academy of Sciences, \\ 142432 Chernogolovka, Russia \\ 2 Institute of Solid State Physics, \\ Russian Academy of Sciences, \\ 142432 Chernogolovka, Russia \\ ${ }^{3}$ National University of Science and Technology \\ „MISiS“, \\ 119049 Moscow, Russia
}

Abstract Effect of nickel or copper introduction during the chemomechanical polishing at room temperature on recombination properties of individual dislocations and dislocation trails is studied by means of EBIC and LBIC techniques. The Ni in-diffusion is observed to increase the recombination activity both of dislocations and dislocation trails. The $\mathrm{Cu}$ introduction results in no evident changes in activity of the extended defects. 